\title{
EL MIEDO CONVENIENTE: LUCHA POR LA TIERRA Y EL CONTROL POLÍTICO LOCAL en el DEPARTAMento DE Chilón, 1871
}

\author{
The Convenient Fear: Fight for Land and the Local Political Control, Chilón Department 1871
}

\author{
Iván Christian López-Hernández
}

Resumen: En Chiapas, entre los años 1841 y 1886, los ladinos del departamento de Chilón sospecharon y denunciaron ante las autoridades civiles que los indios preparaban una rebelión en su contra. El objetivo del presente trabajo es demostrar que el miedo ladino a un ataque indio fue parte de un proceso de larga duración. Además, sostengo que las denuncias y los procesos judiciales en contra de los presuntos sublevados fueron utilizados por los ladinos para confirmar su poder político, económico y social frente a los indios que trataron de defender su autonomía por medios legales y extralegales, pero sin llegar a la rebelión. Con este último objetivo se analizarán las denuncias y los procesos de captura de los presuntos rebeldes de 1871 .

Palabras clave: rebeliones indígenas, lucha por la tierra, politica agraria, control político, siglo XIX.

Abstract: In Chiapas between 1841 and 1886 the Indians of the Chilón Department suspected and denounced in the presence of civiles authority a rebellion or castas warrior. In the present text I will give to know the ladino scared in presence of to an Indian attack it was part of lengthy process. Also, I contend that the denounces and the judicial processes against suspected insurgents were used by ladinos to confirm them their politic power, economic and social in front of Indians, who tried to defend their autonomy through wherewithal legal and extralegal, but without arrive to the rebellion. Under this objective I will analyze the complaints and the process of capturing the suspected rebels of 1871 .

Keywords: indigenous rebellions, struggle for land, agricultural policy, political control, 19th century.

Iván Christian López Hernández, licenciado en Historia por la Universidad Autónoma de Chiapas. Profesor en la carrera de historia de la Universidad Autónoma de Chiapas y asistente en el Archivo Histórico Diocesano de San Cristóbal de Las Casas. Correo electrónico: ivansep23@hotmail.com.
Enviado a dictamen: 27 de junio de 2012

Aprobación: 02 de enero de 2013

Revisiones: 1 


\section{Introducción}

$\amalg$ n Chiapas, y específicamente en el departamento de Chilón, de 1841 a 1886 se difundieron rumores sobre una rebelión que los indios intentarían en contra de los ladinos. Las noticias de sublevación india reavivaron viejos temores que se expresaron en denuncias, informes y amenazas hechas por párrocos, comerciantes y hacendados.

El objetivo del presente trabajo es dar cuenta de cómo el miedo ladino a la sublevación india fue socialmente construido durante la época colonial y cómo esta representación en el imaginario ladino, aunada a factores políticos y a la lucha por la tierra, jugó un papel importante en el desarrollo de los temores, amenazas y denuncias de sublevación en contra de los indios durante el siglo XIX. Asimismo, pretendo demostrar que los procesos de juicio y captura de los presuntos rebeldes no solamente tenían el objetivo de eliminar cualquier aspiración india de sublevación. A mi parecer, el objetivo también fue demostrar a los indios que quienes gobernarían fuera y dentro de los pueblos serían los ladinos.

\section{La construcción mental del enemigo}

El miedo ladino a una sublevación india se fue construyendo desde el periodo colonial. Con la llegada de los españoles y el establecimiento del sistema colonial, la mayoría de la población india quedó relegada al último escalón de la pirámide social y bajo el control político, económico y religioso de españoles conquistadores, religiosos y funcionarios reales. Ante tales circunstancias, la población india trató de mejorar su situación haciendo uso de las leyes vigentes y de las instancias de apelación; en algunos casos llevó a cabo motines o rebeliones en contra de las autoridades del régimen imperante.

En 1532 los chiapanecas tomaron las armas en contra de los españoles y de sus indios amigos. Dicha rebelión fue reprimida rápidamente por las huestes españolas comandadas por Baltasar Guerra y los rebeldes capturados fueron enviados a Copanaguastla para servir como fuerza de trabajo. Las aspiraciones de los indios de Chiapa no terminaron con la primera derrota porque en 1533, liderados por el cacique indio Diego de Nocanoyola, volvieron a rebelarse. El resultado de esta segunda lucha fue desastroso para los indios, que probaron el rigor español en la horca. A partir de aquella derrota el pueblo de Chiapa fue uno de los más leales servidores de la corona española. Durante los ataques en contra de los lacandones y en la batalla de Huixtán durante la rebelión de 1712, indios chiapanecas participaron al lado de las tropas españolas. ${ }^{2}$

A diferencia de la rápida pacificación de los chiapanecas, la resistencia de los pochutlas y de los lacandones se mantuvo durante largo tiempo. Estos dos pueblos se valieron de la geografía accidentada de la selva para resistir los embates españoles, además de atacar pueblos ya pacificados como Bachajón. Los pochutlas fueron pacificados y congregados en un barrio de Ocosingo en 1559, mientras que los lacandones, firmes en su decisión, no fueron sometidos hasta 1695. Para finales del siglo XVII, la belicosidad lacandona, así como su costumbre de sacrificar humanos, era sólo un mito. ${ }^{3}$

García de León enmarca las sublevaciones indígenas producidas en Chiapas en ciclos de resistencia. Uno de estos ciclos se produjo a finales del siglo XVII y principios del XVIII. El motín en Tuxtla en el año 1693 y la rebelión de los Zendales en 1712 fueron parte de ese ciclo.

Lo ocurrido en Tuxtla, donde se dio muerte al alcalde mayor Manuel Maisterra, a su teniente Nicolás Trejo, y al gobernador indio Pablo Hernández, se debió, en parte, a los abusos de los representantes locales del gobierno de la provincia y a la falta de justicia hacia los indios zoques. Y es que poco o nada les valió a los tuxtlecos quejarse ante la Audiencia de Guatemala; las autoridades locales no atendieron con prontitud sus quejas. Fue hasta que corrieron rumores de que los zoques planeaban una rebelión, cuando el alcalde mayor 
decidió ir a Tuxtla. Al llegar a esa ciudad, los indios se presentaron ante el alcalde y le exigieron la destitución del gobernador indio. Maisterra se negó a resolver el asunto el mismo día de su llegada y mandó azotar a un indio principal que se oponía a ello. La negativa de Maisterra y el castigo que se aplicó al indio principal encendió el ánimo de los indios, que desahogaron su frustración apedreando a Maisterra hasta darle muerte y asesinando al gobernador indio y al teniente Nicolás Trejo. Cuando las autoridades españolas llegaron a Tuxtla para castigar a los amotinados, estos estaban arrepentidos y temerosos de los castigos que les esperaban (MacLeod, 2004).

Caso muy diferente a lo ocurrido en Tuxtla fue la rebelión de 1712 en la que participaron pueblos de las provincias de Zendales, Coronas y Chinampas, y de la guardianía de Huitiupán. Aquella sublevación ha sido considerada la más grande e importante del Reino de Guatemala durante la época colonial.

Las causas de esta rebelión, como bien lo señala Viqueira (2004), se inscriben dentro de un proceso de corta, mediana y larga duración. La causa inmediata fue la presión económica que sufrieron los pueblos de dicha provincia y, de alguna manera, el contexto político del momento. A finales del siglo XVII y principios del XVIII, funcionarios reales exigían el tributo en dinero y no en producto como era costumbre. Asimismo, las frecuentes visitas de los obispos, particularmente de Juan Bautista Álvarez de Toledo, aumentaron el descontento. Este obispo cobraba a cada pueblo por derechos de visita, exigía donaciones extras para realizar obras de caridad, pedía a los indios el pago de ocho pesos para rezar por las almas de los cofrades difuntos y reclamaba el pago del diezmo del capital principal de las cofradías. ${ }^{4}$ A causa de estas exigencias tributarias, por la segunda visita del obispo en 1711 y la crisis agrícola en ese año, pueblos como Tila, Chilón, Santa Marta, Yajalón y Cancuc, entre otros, se rebelaron en contra de sus opresores durante los primeros días de agosto de $1712 .^{5} \mathrm{La}$ intensidad de aquella rebelión que puso en predicamentos al gobierno de la provincia y al del propio Reino de Guatemala, y que al final fue sofocada, dio pie para que a partir de entonces españoles y ladinos percibieran a los indios de la zona como indios levantiscos y rebeldes que esperaban el momento oportuno para realizar una nueva sublevación.

El fraile Francisco Ximénez, en su Historia de la provincia de San Vicente de Chiapa y Guatemala de la orden de predicadores, involuntariamente da cuenta de la situación emocional de los españoles después de la sublevación. Ximénez transcribe una carta que el provincial fray Gabriel de Artiga le envía al presidente de Guatemala. En esa carta explica la situación de la región y comenta: "los indios se encuentran más humildes y sosegados y no tienen más ánimo que para humillarse. Artiga recomienda al presidente de la audiencia haga caso omiso de las noticias de una nueva rebelión" (Ximénez, 1999: 219). Seguramente, como indicaba Artiga, para esos momentos los indios ya no tenían intenciones ni ganas de sublevarse, pero el miedo producto de la pasada sublevación hacía efecto en el ánimo español.

Es verdad que algunos españoles he comunicado que todavía sospechan que los indios están reducidos en sus interiores, pero estos recelos juzgo, o bien nacidos de la suma cobardía de algunos, o bien por la conveniencia de otros por parecer que en río revuelto pueden tener ganancias los pescadores (Ximénez, 1999: 282).

En la citada obra de Ximénez se da cuenta de la ferocidad con que los rebeldes atacaron pueblos como el desafortunado pueblo de Yajalón en el que, según este fraile, fueron asesinados todos los españoles varones. Por lo tanto, la obstinada idea de Artiga de convencer al presidente de Guatemala de hacer caso omiso de las noticias de una nueva sublevación en la provincia, y su interés, por señalar la calma en que vivían los pueblos indígenas es un informe involuntario del gran temor e inquietud de la sociedad no india ante la posibilidad de una nueva rebelión. 
En suma, se puede decir que el orden colonial fue aceptado por los indios, que pagaron el tributo, sirvieron como cargadores y como mano de obra y aceptaron la posición política y religiosa impuesta por los españoles, pero también trataron de romper el dominio español, o resistirse a él, de forma pacífica o violenta. Y por otra parte, los ladinos, aunque tenían el derecho que su clase social les daba de dominar al indio, también tenían claro que el orden colonial podía provocar que los indios, cansados del dominio de los españoles, trataran de cambiar su situación por distintos medios.

Tanto el sistema colonial como la resistencia india contribuyeron a que indios y ladinos se percibieran como contrarios, como enemigos.

\section{Los rumores de sublevación y la guerra de castas en Los Altos}

La Independencia de Chiapas en 1821 y su integración definitiva al Estado mexicano en 1824 no significaron para los indios el fin de sus malas condiciones de vida ni el inicio de un cambio a favor de sus derechos laborales y políticos. La relación entre indios y ladinos fue igual o más conflictiva después de 1824. La llegada de ladinos a los pueblos de indios y el interés que estos tenían por las tierras pertenecientes a los pueblos provocaron conflictos entre los dos grupos que se manifestaron en quejas, denuncias y en rumores de sublevación india.

En 1841 los indígenas de Tenango fueron acusados ante el juez de Primera Instancia de intentar una rebelión en contra de los ladinos. ${ }^{6} \mathrm{El}$ expediente de dicha denuncia está extraviado y únicamente sabemos de ésta por el registro que se conserva en el antiguo inventario del Juzgado Mixto de Primera Instancia del departamento de Chilón. Por otra parte, el que el expediente tuviera 101 fojas permite suponer que desde el punto de vista de la justicia ladina era un asunto de gravedad y no un simple rumor sin fundamento, haciendo necesario realizar numerosas averiguaciones e interrogatorios.
Siete años después de la denuncia en contra de los indios de Tenango, se rumoró que los pueblos de Ocosingo, Chilón, Sibacá y Nuevo San Carlos se rebelarían en contra de la clase ladina en el mes de marzo. ${ }^{7}$ El temor ladino y de las autoridades civiles fue mayor en el momento en que se tuvo noticias de que varios indios se habían reunido cerca del pueblo de Chilón para conspirar en contra de los ladinos (Wasserstrom, 1989: 153). En seguida, las autoridades civiles tomaron cartas en el asunto y en vísperas del levantamiento, no obstante que los indios no habían agredido ni física ni verbalmente a los ladinos, capturaron y trasladaron a San Cristóbal a más de 50 presuntos implicados (Rus, 2004: 152).

Desgraciadamente no contamos con los expedientes de los juicios ni con las declaraciones de los detenidos en 1848, pero la liberación de dichos indios tres meses después de su captura permite suponer que las autoridades ladinas no tenían pruebas fehacientes para castigar a los indios por intento de sublevación. Lo que sí es evidente y se revela en los informes parroquiales de aquel año es el descontento de la población india por la llegada de ladinos a sus pueblos y por la enajenación de sus tierras. ${ }^{8}$

En 1852, según Vicente Pineda, hubo indicios de que algunos pueblos del partido de Chilón querían alzarse en contra de los ladinos y en 1859 se denunció ante el juez de Primera Instancia del departamento de Chilón que los indios de Bachajón y de otros pueblos comarcanos tenían planeado sublevarse (Pineda, 1986: 72). ${ }^{9}$ Y si los rumores previos al conato de rebelión de 1871 dan cuenta de un miedo constante de los ladinos, la llamada guerra de castas de 1869, que se desarrolló en Los Altos, puso en estado de alerta a los ladinos del departamento de Chilón.

Sobre la llamada guerra de castas de Chamula se han hecho diferentes estudios. Jan Rus menciona, en su ya clásico artículo sobre el tema, que lo ocurrido en Los Altos entre 1867 y 1869 fue más bien un ataque de los ladinos en contra de los indios que habían 
creado un mercado regional fuera del control de los sancristobalenses y un culto a las piedras parlantes en un contexto político que los favorecía. Por otra parte, Victoria R. Bricker explica en su libro El Cristo indígena, el rey nativo que la llamada guerra de castas fue un movimiento de revitalización religiosa que sólo adquirió proporciones de una cruzada política dedicada al exterminio de los ladinos cuando los sancristobalenses trataron de sofocar el movimiento y detener a sus dirigentes (Bricker, 1993: 235). Pero, icuál fue la lectura que dieron las autoridades y los ladinos de la época a aquellos acontecimientos? Seguramente fue distinta a la versión de Jan Rus y, en ciertos aspectos, parecida a la versión de Bricker. Aunque responder esta pregunta no es el objetivo del presente artículo, trataremos de aproximarnos a una respuesta tentativa que nos ayude a contextualizar lo ocurrido en Chilón en 1871.

Para tener una idea de la versión ladina de lo ocurrido en Los Altos, se tienen que tomar en cuenta las noticias difundidas por los periódicos y por los observadores de la época, así como la posición social y política de los ladinos en aquellos años.

La versión del historiador decimonónico Vicente Pineda bien puede ser la misma que se difundió entre los ladinos de Los Altos y del departamento de Chilón. Este autor explica, con base en las noticias periodísticas y en los hechos que él mismo presenció, que lo ocurrido en Chamula no fue una guerra de castas sino una guerra del salvajismo en contra de la civilización, una guerra de las tinieblas en contra de la luz. Es decir, según Pineda los indios se sublevaron en contra de los ladinos por la naturaleza de su barbarie y no por un odio racial. ${ }^{10}$ Pineda cuenta que desde el año 1867 Agustina Gómez Checheb y Pedro Díaz Cuscat, con el pretexto de rendir culto a unos figurines de barro, se reunían con varios indios para preparar una rebelión en contra de la clase ladina, la cual se inició en junio de 1869:"11

[...] salió el sanguinario y feroz Galindo con sus chusmas, cual pantera hambrienta, a recorrer los pueblos de San Pedro, San Miguel, San Andrés, Santa Marta, Magdalenas, San Pablo, Santiago, Plátanos, Santa Catarina, y todas las haciendas de este rumbo, asesinando a toda la gente ladina que no pudo hallar salvación en la fuga... (Pineda, 1986: 82).

Esta versión de la guerra de castas de Vicente Pineda seguramente es la misma que se difundía entre los ladinos de San Cristóbal por medio de la oralidad y de la prensa. Por ejemplo, durante la guerra de castas, en el periódico La Brújula un pensador coleto se refería a los indios de la siguiente manera:

¿Qué son los indios de Chiapas? Son faltos de instrucción y nada conocen de los deberes morales [...] nada conocen de los deberes civiles, para ellos no hay más autoridad que la fuerza bruta [...] nada conocen de los deberes sociales, pues viven diseminados y errantes como los seres irracionales indómitos... (Connaughton y Vázquez, 2007: 205).

Las noticias de lo ocurrido en Los Altos pusieron en estado de alerta a los ladinos del departamento de Chilón. En 1871, las autoridades ladinas percibieron en una reunión de indios el inicio de una guerra de castas que al parecer sería liderada por un ladino de nombre Martín Rosales, tal como se contaba lo había hecho el ladino Ignacio Fernández de Galindo en Los Altos después de que fueron capturados Checheb y Cuscat.

Las denuncias y rumores de conatos de sublevación nos permiten suponer dos cosas: el persistente miedo que dominaba la mente de los ladinos y la disposición de las autoridades a realizar capturas e interrogatorios a la menor sospecha con el ánimo de apagar cualquier movimiento de resistencia antes de que empezara.

\section{Una presunta rebelión en 1871}

En el mes de julio de 1871 se organizó la guardia nacional que sujetaría a los indios rebeldes del departamento de 
Chilón. Durante aquella incursión, fueron capturados 65 indios de Bachajón, Cancuc, Chilón, Ocosingo, Petalcingo, Tumbalá y Yajalón bajo el cargo de intento de sublevación. ${ }^{12}$ No obstante la captura de los indios, habría que preguntarse, irealmente los indios querían sublevarse y por tal motivo las autoridades actuaron rápida y violentamente en contra de los presuntos rebeldes? En el presente apartado se intenta resolver dicha interrogante mientras se narra lo acontecido.

Desafortunadamente no se tiene registro del momento en que comenzaron los rumores de sublevación ni de la fecha exacta de las denuncias que provocaron la captura de los indios. Tampoco se tiene registro de la totalidad de los pueblos que se decía estaban comprometidos con la rebelión y, aunque la procedencia de los capturados nos da un número aproximado de los pueblos implicados, tampoco hay que descartar que los indios de los pueblos de Sitalá, Guaquitepec, Tenango, Sibacá, San Martín y Oxchuc hayan estado implicados en la presunta sublevación pues, como lo declararon varios soldados de la guardia nacional, fueron varios pueblos del departamento de Chilón los que participarían en la presunta rebelión.

La guardia nacional encargada de capturar a los implicados y reprimir cualquier intento de rebelión quedó conformada por Manuel Waldo Salazar, jefe político del departamento, comandante de las fuerzas y jefe de la compañía que resguardaría el orden desde el pueblo de Chilón; por Matías Parada, prominente político, hacendado de la región y jefe de la compañía militar que se instaló en Ocosingo junto con el jefe de infantería, Abraham Trinidad Vives; y los sargentos, cabos y soldados - que eran vecinos ladinos del departamento de Chilón-, así como algunos mozos de las fincas de la región.

Waldo Salazar recorrió con su compañía los pueblos de Cancuc, Chilón, Yajalón, Tumbalá y Petalcingo, mientras que la compañía bajo el mando de Parada y Vives bien pudo ocuparse de los pueblos de Bachajón, Sibacá, San Martín, Tenango y Oxchuc. ${ }^{13}$
Durante las pesquisas e interrogatorios en Chilón, el indio Marcial Vilches confesó que algunos indios de su pueblo, como Gabriel López, tramaban una sublevación en contra de los ladinos. ${ }^{14}$

En Cancuc, la captura de los involucrados comenzó en cuanto el preceptor de primeras letras, Ambrosio Guillén, tuvo noticia de la reunión que llevaron a cabo varios indios con el ladino Martín Rosales en los alrededores del pueblo. Aquella noticia, dadas las condiciones del momento y el recuerdo de la guerra de castas —en la cual, según los periódicos de la época, el ladino Ignacio Fernández de Galindo fue el líder de los indios-, se interpretó como parte de los preparativos de los indios de Cancuc para secundar la rebelión que, se decía, se realizaría en el departamento.

Conviene aquí detener la narración para presentar cómo es descrito Galindo por la pluma del historiador decimonónico Vicente Pineda y cómo fue descrito Martín Rosales por el preceptor de primeras letras de Cancuc.

Según Pineda, Galindo era "[...] abandonado en el acto sus vestidos propios por un sombrero de palma, un chamarro prieto de lana burda y un taparrabo..." (1986: 79).

Ambrosio Guillen declaró que al momento de detener a Rosales lo encontró: "[...] disfrazado con un sombrero viejo, pequeño y de palma, un chamarrito viejo, en calzoncillo y descalzo y la cintura amarrada con una faja de majagua..."15

Como se lee, la descripción de Rosales es muy parecida a la de Vicente Pineda, por lo que resulta comprensible el hecho de que los ladinos temieran que en el departamento de Chilón se llevara a cabo una rebelión. También permite suponer que la presencia del ladino traidor y líder de los rebeldes fue parte del discurso legitimador de las autoridades civiles para realizar acciones armadas en contra de los indios.

Después de que Rosales junto con 16 indígenas fue apresado bajo el cargo de intento de sublevación, se decomisaron 150 escopetas — que al parecer estaban 
descompuestas-, a las esposas de los implicados se les exigió el pago de tres pesos de multa — aun cuando sus esposos fueron liberados por falta de pruebas-y además se impuso a todo el pueblo una multa colectiva por el delito de sublevación. ${ }^{16}$ Sin miramientos, Salazar, que era el jefe de la tropa, estaba sacando provecho de la situación.

En el pueblo de Bachajón, Francisco Pérez fue asesinado cuando intentaba huir, mientras que por órdenes de Salazar su ganado era confiscado por José Máximo Aguilar y por el gobernador indio Pascual Vásquez. Según lo declarado por la esposa de Pérez, los caballos arrebatados por el jefe político fueron subastados en Ocosingo. Asimismo, el oficial Bonifacio Jerez le arrebató al indígena Mariano Díaz un caballo.

En Chilón, los indígenas Domingo y Marcial Vilches, Deodoro Vásquez y Flavio Rodríguez, recluidos en la cárcel de Chilón, fueron apaleados por los soldados que los custodiaban. Según los indios, fue el propio Waldo Salazar quien ordenó que se les castigara. Sobre estos excesos, el jefe político Salazar declaró que, aunque él no había dado la orden a sus soldados:...

[...] ese abuso [el castigo corporal] no era muy remoto que se hubiera cometido, puesto que los soldados y los individuos todos del departamento de Chilón estaban sumamente indignados en contra de la raza indígena, por la guerra de castas estallada entonces. ${ }^{17}$

El soldado José Eugenio Rodríguez asestó un machetazo a un indio que se atrevió a gritarle. Rodríguez declaró que, al comunicar lo sucedido al jefe de la guardia Abraham Trinidad Vives, éste le respondió "que estaba bueno, pero no del todo porque no lo había terminado de matar." ${ }^{18}$ A los presuntos sublevados Sebastián Montejo del pueblo de Tumbalá, Manuel Martínez de Petalcingo, Sebastián López de Bachajón y al chilonteco Gabriel López se les aplicó la ley fuga. Sobre el asesinato de Montejo, los indios Domingo y Marcial Vilches declararon que el soldado Liévano, que en ese momento estaba ebrio, mató a Montejo porque no podía caminar. Sobre la muerte del chilonteco, los soldados Antonio López y Manuel y Eleuterio Cañas, encargados de arrestar al sospechoso, explicaron que éste se resistió al arresto y que al intentar huir lo asesinaron. Lo revelador del caso es que la muerte de Gabriel López parece haber sido más un acto motivado por el resentimiento que los ladinos tenían en contra de los presuntos sublevados que un intento fallido de detención, pues el fugitivo fue rematado por sus captores cuando ya estaba en el suelo. En Chilón, Manuel Waldo Salazar exhibió ante los indios detenidos el cuerpo de Sebastián López y amenazó a los presos diciéndoles que el mismo destino correrían si intentaban huir.

En las cárceles de San Cristóbal, donde fueron remitidos todos los detenidos, murieron dos de Petalcingo, uno de Bachajón y uno de Yajalón. La muerte de los presos bien pudo deberse al maltrato que recibieron de los guardias que los custodiaban o a las condiciones insalubres de las cárceles.

En el mes de septiembre de 1871, Bonifacio Jerez, al mando de una fuerza militar, condujo a San Cristóbal a los 65 reos acusados de sublevación que estaban recluidos en la cárcel de Chilón. Desgraciadamente no se tienen datos de los reos acusados por el mismo delito que estaban presos en las cárceles de Ocosingo, por lo que no podemos dar cuenta de una cifra aproximada del total de indios detenidos en 1871. Pero los 65 indios que condujo Jerez quedaron presos en las cárceles de San Cristóbal durante todo un año hasta que fueron liberados en julio de 1872 .

$\mathrm{Al}$ igual que en los rumores anteriores, no hubo pruebas fehacientes que constataran que en 1871 los indígenas del departamento de Chilón se hubieran querido alzar en contra de los ladinos, ni mucho menos que haya sucedido algún enfrentamiento armado entre indios y ladinos. En 1875, el Juzgado de Distrito de Chiapas, cuando se ocupó de esclarecer la muerte de cinco indios acusados de intento de rebelión, calificó lo ocurrido en Chilón como un "presunto" intento de 
sublevación. Esto hace suponer que las autoridades del estado nunca supieron si los indios de los departamentos de Chilón en verdad querían sublevarse. La captura de los "presuntos" implicados en la "supuesta" sublevación se debió al temor a que se repitiera en el departamento de Chilón lo ocurrido en Los Altos dos años atrás o, peor aún, lo ocurrido en 1712 en las provincia de los Zendales, Coronas y la Guardianía de Huitiupán.

El estado emocional de los ladinos de la zona en aquel año permite hacer suponer que un ladino temeroso de Bachajón, Chilón u otro pueblo, basado en un acontecimiento a su parecer sospechoso, denunció a los indios por urdir una sublevación en contra de su clase. Por ejemplo, en 1848 los ladinos creyeron que los indios querían rebelarse en su contra en cuanto tuvieron noticias de que en las cercanías del pueblo de Chilón varios indios realizaban una reunión. Durante la guerra de castas en Chamula se dijo que Galindo adiestraba y organizaba militarmente a los indios en el monte, pero al parecer, como menciona Justus Fenner, eso bien pudo ser la percepción de un ladino temeroso que vio en las diligencias para la medición de la tierra los preparativos de una inminente rebelión india -el supuesto líder de los rebeldes era un agrimensor (Fenner, 2011) - . En 1881 se interpusieron en Chilón y en Yajalón dos denuncias en contra de los indios por intento de sublevación basadas en el miedo, las suposiciones y los malos entendidos. En Yajalón, las averiguaciones comenzaron cuando un ladino denunció que un indio en estado de ebriedad amenazó a su esposa: "[...] a donde iban a ir [los ladinos], que los tenía a todos en su pecho, [y que] solo dos o tres días les faltaba pues a traición los iban a matar..."19

En suma, el temor ladino a sufrir un ataque indio provocó en estos un estado de alerta intenso al grado de que percibieron, por una reunión entre indios o en las palabras proferidas por un indio ebrio, la trama de una rebelión. Y, por otra parte, las autoridades y hacendados de la región descubrieron en las denuncias por intentos de rebelión india una buena oportunidad para reprimir cualquier movimiento de resistencia india y consolidar su poder en la región por medio de la represión y la violencia - con recursos legales y extralegales- en contra de los indios que se resistían al dominio ladino.

\section{La lucha por la tierra y el control político local: entre la legalidad y la amenaza}

Para comprender lo ocurrido en 1871 hay que tener presente que la oposición entre indios y ladinos y la representación del indio enemigo en el imaginario ladino cobraron fuerza durante el siglo XIX a causa de la migración y la lucha por la tierra en el departamento de Chilón.

La migración ladina hacia las antiguas repúblicas de indios fue sin duda factor capital en los conflictos que se desarrollaron en el departamento de Chilón durante el siglo XIX. En la época colonial, por ley, ni españoles ni ladinos podían vivir dentro de los pueblos de indios, ni mucho menos hacerse de tierras dentro de estos. Aunque esta ley no se respetó del todo, sí frenó la llegada de ladinos a los pueblos de indios. Al finalizar la colonia no sólo se derogó esta ley, sino que se promovió por medio de las leyes agrarias la colonización de tierras baldías. Es decir, que desde 1826, año en que se promulgó la primera ley agraria, se impulsó el denuncio de tierras baldías y de manera indirecta se promovió la migración ladina hacia tierras antes prohibidas para los ladinos.

La llegada de los migrantes a los pueblos no fue bien vista por los indios del departamento de Chilón. En primer lugar, porque en el imaginario colectivo tanto indios como ladinos se percibían como contrarios, y en segundo lugar porque la intención de los ladinos era hacerse con las tierras y el control político y económico de la región.

En 1848, el cura Ramírez informaba que los indios se preguntaban: "ipor qué causa se han venido los ladinos a vivir entre nosotros, cuando en la antigüedad aparte vivían los indios y aparte los ladinos?" ${ }^{20}$ En ese mismo 
año, el cura de Sitalá y Guaquitepec informó que, debido a que no hay vecinos ladinos en los pueblos a su cargo, no ha observado en los indios intenciones de sublevarse. El padre advierte que los indios bien pueden secundar la rebelión que inicien otros pueblos porque están inconformes con las mediciones de sus tierras. ${ }^{21}$ Clemente Castillejo, cura de Yajalón, informaba que en 1849, en el pueblo a su cargo, ya había 92 ladinos y que en 1842 los indios de Yajalón vieron amenazadas sus tierras cuando el ladino Serapio Cancino denunció dos terrenos que pertenecían a aquel pueblo. ${ }^{22}$ Dicha denuncia no se concretó porque el padre Castillo intervino a favor de los indios. En el año 1839, cuando se hizo la mensura del ejido de Ocosingo, los indios salieron perjudicados pues las mejores tierras quedaron fuera del fundo del ejido. Según Mariano Ramírez de Páramo, párroco de Ocosingo y sus anexos San Carlos y Sibacá, en 1848 las mejores tierras de la región no fueron reconocidas como parte del ejido, sino que fueron concedidas a los ladinos que formaban parte de la camarilla del señor Parada. Según el párroco, Parada trataba de colocar en los puestos del gobierno local a personas de su propio grupo con la intención de que los indios no tuvieran ninguna instancia de apelación que los apoyara. ${ }^{23}$ En 1879 Miguel Andrés Parada era el secretario de la presidencia municipal de Sitalá. ${ }^{24}$

En 1871, el conflicto entre indios y ladinos en el departamento de Chilón hacía varios años que había comenzado. Lo interesante de este conflicto es que los indios hicieron uso de las leyes agrarias y aprovecharon el contexto político estatal, en ciertos años volcado a su favor, para asegurar sus tierras que no estaban amparadas por el ejido. En 1867, el gobierno del estado envió, por orden de la Secretaría de Fomento, una circular a los departamentos en la que se pedía a los jefes políticos que en la adjudicación de terrenos baldíos no salieran afectados los terrenos que poseían los pueblos y que exhortaran a los indios para que reclamaran de manera individual los títulos de propiedad de los terrenos que tenían ocupados. ${ }^{25}$ Aparte de lo dispuesto por el gobierno federal, el gobernador Pantaleón Domínguez, a través de los secretarios y maestros de escuela, comenzó una campaña de politización que consistía en dar a conocer a los indios sus derechos civiles. ${ }^{26}$ La posición del gobierno federal y del gobierno estatal fue un duro golpe para los ladinos que pretendían hacerse con el control político y económico en los pueblos del departamento de Chilón. Como bien señala Leticia Reina, en un país donde escasea el capital para invertir en el comercio o en la manufactura de productos, la tierra se mantiene como la principal fuente de riqueza y poder (Reina, 1980: 16).

La Ley Agraria del 20 de julio de 1863, decretada por Benito Juárez, fue la que reglamentó los denuncios de tierra hechos por particulares. En 1867, el barrio de San Sebastián del pueblo de Bachajón denunció un terreno nacional ante la Jefatura Superior de Hacienda y la Agencia del Ministerio de Fomento. El denuncio fue aceptado y se notificó a los solicitantes que el monto a pagar por el terreno sería de 1087.66, 31/4 pesos a liquidar en tres plazos. ${ }^{27}$ En ese mismo año, los indígenas bachajontecos del barrio de San Jerónimo, Gaspar Moreno, Pascual Feliciano y Juan Hernández, pidieron que se realizara el avalúo de un terreno que ya tenían mensurado, el cual contaba con una superficie de 7081 hectáreas, 67 áreas y 96 centiáreas. ${ }^{28}$ Debido a que el denuncio de Gaspar Moreno y sus socios cumplía con los requisitos de la Ley del 20 de julio de 1863, la liquidación fue practicada y se les comunicó que el monto a pagar por el terreno sería de 4540.89 pesos. ${ }^{29}$ Casualmente la mayoría de los detenidos en 1871 por intentos de sublevación fueron indios de Bachajón.

La invasión de los terrenos que estaban en disputa fue otro de los recursos utilizados por los indios en la lucha por la tierra. En 1873, Justo Trujillo se quejó ante el juez de Primera Instancia de Chilón de que los indios del paraje El Palmar tenían invadido desde 1867 su terreno llamado Zaphaltan. ${ }^{30}$ Según el demandante, los indios fueron motivados a invadir sus tierras por el exjuez de Primera Instancia Manuel F. Cancino. Trujillo pidió al 
nuevo juez que exigiera a los invasores el pago de 380 pesos, costo de la denuncia y del deslinde del terreno, y el pago de los bienes muebles que se encontraban en dicha propiedad. Según el demandante, esta deuda no fue cobrada en 1867 porque una enfermedad le imposibilitó continuar con la solicitud. Seis años después de dicha invasión, Trujillo pidió al juez que exigiera a los indígenas que le pagaran el terreno y los daños causados a sus propiedades. Es muy probable que esta invasión haya sido producto de la politización indígena desarrollada desde 1867 y que Justo Trujillo haya tenido que esperar a que las condiciones políticas le fueran favorables para denunciar a los indios.

En 1873, José Rojas, apoderado de Eustaquio Domínguez, puso una queja en contra de los indios de Guaquitepec por la invasión de terrenos pertenecientes a la hacienda Corazón de María, propiedad de su poderdante. ${ }^{31}$ En la queja se pidió al juez que comunicara a los indios que si no se retiraban de las tierras de Domínguez perderían lo trabajado y pagarían por los daños ocasionados. Rojas declaró que los indios de Guaquitepec fueron motivados por el jefe político del departamento, Manuel Waldo Salazar. Por otra parte, el hacendado Agustín Díaz, quien tenía problemas de colindancias con Eustaquio Domínguez, afirmó que Rojas, como apoderado de Domínguez, había invadido terrenos del pueblo de Guaquitepec.

Los indios de Oxchuc y los hermanos Pineda desde 1861 se enfrascaron en un pleito por un terreno que mediaba entre la hacienda El Retiro, propiedad de los Pineda, y el ejido de Oxchuc. ${ }^{32}$ El pleito comenzó cuando los indios de Oxchuc se negaron a pagar el baldiaje a los Pineda alegando que las tierras donde tenían sus sementeras quedaban fuera de los límites del ejido de Oxchuc y de la hacienda El Retiro. Como efecto de estas diferencias, el ayuntamiento del pueblo y demás justicias midieron los límites de la finca El Retiro y los del ejido de Oxchuc. El resultado de la medición fue favorable para los hermanos Pineda. Los indios que quedaron dentro de los límites de la finca El Retiro no tuvieron más remedio que pagar el baldiaje a los Pineda. ${ }^{33}$ Pero el pleito continuó. En 1868 los vecinos de Oxchuc se negaron a pagar el baldiaje a los propietarios de la finca El Retiro y pidieron a las autoridades que se librara una orden para verificar los límites entre el ejido y los de la finca El Retiro. A petición de los indios se realizó de nueva cuenta la medición de los terrenos. En 1878 este mismo pleito volvió a ser presentado por Leonardo Pineda ante el Juzgado de Primera Instancia de Chilón. ${ }^{34}$

Desgraciadamente, las fuentes hasta ahora consultadas no permiten conocer la totalidad de los pueblos del departamento que utilizaron las leyes agrarias o invadieron terrenos que disputaban a los ladinos, pero es muy probable que varios pueblos hayan tomado medidas para proteger o recuperar tierras que antiguamente les pertenecían. En 1876, indios de Yajalón denunciaron un terreno ubicado entre Salto de Agua, Tumbalá y Yajalón en el cual fundaron, junto con cien familias, el paraje Chacabanté.

En suma, el hecho de que los indios se reorganizaran para denunciar terrenos baldíos e invadieran terrenos perdidos pudo infundir temor en los ladinos del departamento de Chilón. Esta oleada de luchas legales y extralegales por la tierra bien pudo ser interpretada como el primer paso para un movimiento rebelde. ${ }^{35}$ Asimismo, los rumores y denuncias de sublevación india que se desarrollaron en el departamento de Chilón desde 1841 y la guerra de castas ocurrida en Los Altos fundamentaron las sospechas ladinas de que una rebelión india se podía gestar en su contra. Bajo tal estado de tensión los ladinos podían percibir en una reunión india o en una plática entre indios de diferentes pueblos la trama de una rebelión en su contra, por lo que no dudarían en denunciarlos.

Por otra parte, las autoridades del departamento, junto con los vecinos ladinos de los diferentes pueblos implicados en los conatos de sublevación, vieron en la denuncia de rebelión un medio para ratificar y dejar en claro su supremacía política. Querían probar a 
los indios que bastaba con acusarlos de intentos de sublevación para que las autoridades del estado los reprimieran violentamente. Es decir, que las autoridades y los hacendados ladinos del departamento utilizaron el miedo ladino a la rebelión india a conveniencia y así confirmaban su posición política en el departamento de Chilón por medio de la amenaza y la violencia. En 1876, se acusó a Waldo Salazar de que en 1871, cuando capturó a los presuntos sublevados, aprovechó para que se hicieran las elecciones de alcaldes y regidores para el año $1872 .^{36}$ En 1881 el ladino Alejandro Lara, al escuchar que dos indios, uno de Tenejapa y otro de Bachajón, platicaban de forma sospechosa, los amenazó diciéndoles "[...] que ya había oído lo que estaba tratando con su compañero del pueblo de Bachajón y que no creyera que ellos quedarían contentos, pues ya vendrían fuerzas del interior o de México y que también acabarían todos..." ${ }^{\text {37 }}$

Los vecinos ladinos, como autoridades del departamento, utilizaron a su favor el miedo ladino para asegurar su posición social y política en la región.

\section{Notas}

${ }^{1}$ El departamento de Chilón fue una entidad administrativa creada en 1859, un espacio geográfico y social conformado por varios de los pueblos que durante el periodo colonial pertenecieron a la provincia de los Zendales, como los pueblos de Ocosingo, Chilón, Cancuc, Bachajón, Oxchuc, Sitalá, Tenango, Guaquitepec, Sibacá, San Carlos y San Martín.

2 Sobre la doble rebelión de los chiapanecas véase De Vos (1990).

${ }^{3}$ Sobre los lacandones de la época colonial véase De Vos (1996).

${ }^{4}$ El término principal es la cantidad con la que una cofradía comienza a funcionar, es decir, el capital que posee una cofradía.

${ }^{5}$ Sobre esta rebelión véase Viqueira (2004) y Martínez Peláez (s.f.).
${ }^{6} \mathrm{AHJCH}$, "Contra los indígenas del pueblo de Tenango por sublevación", 1841, exp. 104. (Documento extraviado. Solamente se encuentra registrado en el antiguo inventario).

${ }^{7}$ AHDSC, "Mariano Ramírez de Páramo, cura doctrinero del pueblo de Ocosingo, Informe sobre un conato de rebelión en la región por sentirse los indios en su propio pueblo cada vez más desplazados por los ladinos". Ocosingo, junio de 1848. Este documento fue transcrito por De Vos (1994, 258-260).

${ }^{8}$ En el cuarto apartado se analizarán los conflictos por la tierra entre indios y ladinos.

9 Véase también AHJCH, "Diligencias practicadas en averiguación de la revelación que intentan los indígenas de Bachajón y otros pueblos contra esta villa", 1859, exp. 260.

${ }^{10}$ Cabe aclarar que el autor se contradice constantemente y durante su relato presenta lo ocurrido como una guerra de castas.

"I Sobre la figura del enigmático Galindo y su participación en los acontecimientos de 1869, Fenner (2011) proporciona nuevos elementos para una nueva interpretación.

$12 \mathrm{AHJCH}$, "Criminal contra los que aparezcan responsables de los homicidios perpetrados en varios indígenas acusados del presunto delito de sublevación", 1975, exp. 869. Sobre los acontecimientos ocurridos en 1871 contamos con dos documentos, el que se acaba de citar y el exp. 913. Afortunadamente, los dos documentos ofrecen valiosa información acerca de cómo se desarrollaron las acciones militares en contra de los indios.

${ }^{13}$ No se sabe con exactitud cuáles fueron los pueblos recorridos por Vives y Parada; sólo se tiene el dato de que instalaron un cuartel en Ocosingo.

${ }^{14}$ La mayor parte de este relato está basada en el exp. 869 del Archivo del Juzgado Mixto del departamento de Chilón, por lo que en este apartado únicamente señalaré las fuentes cuando los datos sean tomados de otro documento. 
$15 \mathrm{AHJCH}$, "Escrito presentado por Manuel Waldo Salazar", 1876, exp. 913.

$16 \mathrm{AHJCH}$, "Escrito presentado por Manuel Waldo Salazar", 1876, exp. 913.

${ }^{17} \mathrm{AHJCH}$, "Criminal contra los que aparezcan responsables de los homicidios perpetrados en varios indígenas acusados del presunto delito de sublevación”, 1975, exp. 869. No es claro si la guerra de castas a la que hace alusión Waldo Salazar es la de Los Altos en 1869 o se refiere a lo que ocurrió en el departamento de Chilón en 1871.

$18 \mathrm{AHJCH}$, "Criminal contra los que aparezcan responsables de los homicidios perpetrados en varios indígenas acusados del presunto delito de sublevación", 1975, exp. 869.

${ }^{19} \mathrm{AHJCH}$, "Diligencias practicadas sobre la sublevación que intentan los indígenas en contra de nuestra clase", 1881, exp. 932.

${ }^{20}$ Dato proporcionado por el doctor Jan Rus. Documentos que transcribió del AHDSC.

${ }^{21}$ AHDSC-Fondo Diocesano, carpeta 3105, exp. 1.

${ }^{22}$ AHDSC-Fondo Diocesano, carpeta 3203, exp. 4.

23 AHDSC-Fondo Diocesano, carpeta 2971, exp. 2. Posiblemente el señor Parada a que se refiere el cura Ramírez de Páramo sea Matías Parada, jefe de la tropa que se instaló en Ocosingo en 1871 para capturar a los presuntos rebeldes.

${ }^{24}$ AHDSC-Fondo Diocesano, carpeta 3112, exp. 1.

${ }^{25}$ AHDSC-Fondo Diocesano, carpeta 2658, exp. 1.

${ }^{26}$ Según Rus, la politización de los indios fue un factor importante para que el pueblo Chamula y pueblos comarcanos realizaran el movimiento autonomista y religioso de 1869, interpretado por las autoridades religiosas y civiles de San Cristóbal como una guerra de castas.

${ }^{27} \mathrm{AHJCH}$, "Liquidación de varios indígenas del pueblo de Bachajón por terrenos que tienen mensurados", 1867, exp. 675 .

28 Seguramente estos tres indígenas actuaban en representación de un grupo más numeroso, posiblemente todos los vecinos del barrio de San Jerónimo.
${ }^{29} \mathrm{AHJCH}$, "Liquidación de varios indígenas del pueblo de Bachajón por terrenos que tienen mensurados", 1867, exp. 675.

${ }^{30}$ Según Becerra (1880:283), en el municipio de Altamirano, distrito de Chilón, se encuentra un rancho con el nombre de Sapaltón. Probablemente sea el mismo al que se refería Justo Trujillo en 1873.

${ }^{31} \mathrm{AHJCH}$,"José Rojas apoderado de Eustaquio Domínguez contra indígenas de Guaquitepec", 1873, exp. s/n.

$32 \mathrm{AHJCH}$, "Juicio de apeo y deslinde del terreno denominado El Retiro", 1878, exp. 1011.

$33 \mathrm{AHJCH}$, "Juicio de apeo y deslinde del terreno denominado El Retiro", 1878, exp. 1011.

$34 \mathrm{AHJCH}$, "Juicio de apeo y deslinde del terreno denominado El Retiro", 1878, exp. 1011.

${ }^{35} \mathrm{AHJCH}$, "Diligencias practicadas sobre la sublevación que intentan los indígenas en contra de nuestra clase", 1881, exp. 932.

$36 \mathrm{AHJCH}$, "Escrito presentado por Manuel Waldo Salazar", 1876, exp. 913.

$37 \mathrm{AHJCH}$, "Escrito presentado por Manuel Waldo Salazar", 1876, exp. 913.

\section{Bibliografía}

Becerra, Marcos E. (1880), Nombres geográficos de indígenas del estado de Chiapas, México: Consejo Editorial del Estado de Tabasco.

Bricker, Victoria, R. (1993), El Cristo indígena, el rey nativo, México: FCE.

Connaughton, Brian y Mario Vázquez Olivera (2007), "Tierras del sur: ecuaciones distintas", en Escobar Ohmstede, Antonio, Los pueblos indios en los tiempos de Benito Juárez México: UAM/UABJO.

De Vos, Jan (1990), La batalla del Sumidero, México: CONACULTA/INI.

De Vos, Jan (1994), Vivir en frontera. La experiencia de los indios de Chiapas, México: CIESAS/INI.

De Vos, Jan (1996), La paz de Dios y del rey. La conquista de la Selva Lacandona (1525-1821), México: FCE. 
Fenner, Justus (2011), Ignacio Fernández de Galindo y la Guerra de Castas, una historia y dos memorias. Ponencia presentada en el VIII Encuentro Regional Sur Sureste de Estudiantes de Historia, San Cristóbal de Las Casas, 2 al 6 de mayo.

García de León, Antonio (1999), Resistencia y utopía. Memorial de agravios y crónica de revueltas y profecías acaecidas en la provincia de Chiapas, durante los últimos quinientos años de su historia. México: Era.

Lenkersdorf, Gudrun (2001), Génesis histórica de Chiapas (1522-1532). El conflicto entre Portocarrero y Mazariegos, México: UNAM.

MacLeod, Murd (2004), "Motines y cambios en las formas de control económico y político: los acontecimientos en Tuxtla, 1693", en Viqueira, Juan Pedro y Mario Humberto Ruz (eds.), Chiapas, los rumbos de otra historia, México: UNAM/CIESAS.

Martínez Peláez, Severo (s.f.), Motines de indios. La violencia colonial en Centro América y Chiapas, México: Universidad Autónoma de Puebla.

Pineda, Vicente (1986), Sublevaciones indígenas en Chiapas, México: INI.

Reina, Leticia (1980), Rebeliones campesinas en México (18191906), México: Siglo XXI.
Rus, Jan (2004), “iGuerra de castas según quién? Indios y ladinos en los sucesos de 1869", en Viqueira, Juan Pedro y Mario Humberto Ruz (eds.), Chiapas, los rumbos de otra historia, México: UNAM/CIESAS.

Ruz, Mario Humberto (1992), Savia india, floración ladina. Apuntes para una historia de las fincas comitecas (siglo XVIII y XIX), México: CONACULTA.

Viqueira, Juan Pedro (2004), "Causas de una rebelión india: Chiapas, 1712", en Viqueira, Juan Pedro y Mario Humberto Ruz (eds.), Chiapas, los rumbos de otrahistoria, México: UNAM/CIESAS.

Wasserstrom, Robert (1989), Clase y sociedad en el centro de Chiapas, México: FCE.

Ximénez, Francisco (1999), Historia de la provincia de San Vicente de Chiapa y Guatemala de la orden de predicadores, México: CONECULTA.

\section{Archivos consultados}

Archivo Histórico Diocesano de San Cristóbal de Las Casas (AHDSC).

Archivo Histórico del Juzgado Mixto de Primera Instancia del departamento de Chilón (AHJCH) 